\title{
Colonization of Potato by Colletotrichum coccodes: Effect of Soil Infestation and Seed Tuber and Foliar Inoculation
}

\author{
J. S. Pasche, R. J. Taylor, and N. C. Gudmestad, Department of Plant Pathology, North Dakota State University, \\ Fargo 58102
}

\begin{abstract}
Pasche, J. S., Taylor, R. J., and Gudmestad, N. C. 2010. Colonization of potato by Colletotrichum coccodes: Effect of soil infestation and seed tuber and foliar inoculation. Plant Dis. 94:905-914.

Colonization of potato (Solanum tuberosum) tissue, including roots, stolons, and above and below ground stems, by Colletotrichum coccodes, the causal agent of black dot, was evaluated following soil infestation, inoculation of seed tubers and foliage, and every combination thereof, in field trials over two growing seasons in North Dakota and Minnesota. A total of 107,520 isolations for $C$. coccodes performed across four site-years allowed for an extensive comparison of fungal colonization of the host plant and disease severity. The black dot pathogen was detected in potato stems at the first sampling date in all four site-years, as early as 14 days prior to emergence. Colonization of above and below ground stems occurred at a higher frequency than in roots and stolons in all four site-years, resulting in significantly higher relative area under the colonization progress curves (RAUCPCs) $(\alpha=0.05)$. Although fungal colonization and disease incidence were higher in inoculated and/or infested treatments, sufficient natural inoculum was present to result in substantial levels of disease in noninoculated and noninfested plots. However, noninoculated and noninfested plots displayed the lowest RAUCPC values across three of four site-years and those treatments with multiple inoculation events tended to have higher RAUCPC values. Isolates belonging to vegetative compatibility group (VCG) 2 and -5 were recovered from plants sampled in 2004 more frequently than isolates belonging to VCG1 and -3. A significant difference in disease incidence on stems was observed only in North Dakota in 2004 and Minnesota in $2003(\alpha=0.05)$. Noninoculated and noninfested plots displayed the lowest disease incidence, whereas those treatments with more than one inoculation and/or infestation event tended to have higher disease incidence. Results of this study, including the disease severity and yield data, provide a better understanding of colonization of potato plants by $C$. coccodes and its impact.
\end{abstract}

Black dot, caused by Colletotrichum coccodes (Wallr.) S. Hughes, is a disease that occurs wherever potato crops (Solanum tuberosum L.) are grown. Although the most economically important hosts of C. coccodes are potato, tomato, and pepper, this pathogen is able to infect a wide range of plant species, a majority of them members of the Solanaceae family. Several weed species, including some solanaceous species, also have been identified as hosts $(33,37)$. On potato, black dot generally is considered to be primarily a tuber blemish disease resulting in symptoms similar to silver scurf caused by Helminthosporium solani Durieu \& Mont.; however, the pathogen also can infect roots, stolons, stems, and foliage $(1,3,13,21,27,36,50)$. Infected areas of tubers are silver to brown in color with microsclerotia present. Deep sunken lesions (18) and tuber shrinkage (20) also have been noted with severe in-

Corresponding author: Neil C. Gudmestad

E-mail: neil.gudmestad@ndsu.edu

Accepted for publication 3 April 2010.

doi:10.1094/PDIS-94-7-0905

(C) 2010 The American Phytopathological Society fections. Dark lesions form on infected leaf and stem tissue and contribute to wilting and defoliation $(9,23)$. In severe cases, the cortical tissue of infected below ground stems and stolons may slough off, resulting in a frayed or stringy appearance (9). Upon vine desiccation and disintegration of the cortex, an area of amethyst coloration may be observed in association with the remnants of the vascular bundles (13).

Black dot has been recognized as a disease of potato since the early part of the 20th century (13). It generally had been considered to be of minor importance $(24,35,40,46,48)$, having little impact on commercial potato production in most growing areas. Several factors have contributed to this view, many of which may be related to misdiagnosis. As with other typical anthracnose pathogens, C. coccodes often infects the host early and symptoms are not expressed until much later in the growing season (1), at which point they are often mistaken for normal plant senescence and saprophytic colonization. C. coccodes also can cause early dying in potato similar to other diseases such as Verticillium wilt, caused by Verticillium dahliae Kleb. and V. albo-atrum Reinke \& Berthold, as well as early blight, caused by Alternaria solani Sorauer, and often occurs in conjunction with these diseases. Co-infection with $V$. dahliae has been shown to result in greater reductions than observed with either pathogen alone (51). Although yield losses of up to $30 \%$ due to black dot have been documented, it has proven difficult to reproduce these losses across growing seasons under field conditions, even when differences in black dot symptoms were noted among treatments $(27,28,50)$. Yield losses due to black dot also have been documented in the absence of symptom expression (3).

Because of the aforementioned yield and quality losses, as well as losses reported by commercial potato growers, black dot research has garnered renewed interest in recent years as a developing threat to potato production and crop quality $(25,52)$. The apparent emergence of black dot as an important disease of potato simply may be due to increased awareness of the factors outlined above. Changes in tillage and other cropping practices during the later part of the past century also may have promoted the accumulation of soilborne sclerotial inoculum $(12,41,47)$, because the pathogen's longevity in the soil has been demonstrated to extend 5 to 13 years in the absence of a potato crop $(4,14)$. Although crop rotation may be successful in reducing soil inoculum, the wide host range of $C$. coccodes, including both weed and rotational crop hosts, as well as the longevity of the microsclerotia render crop rotation a fairly impractical control measure $(9,15,33,37)$. Additionally, the large, heavily melanized microsclerotia of $C$. coccodes are not killed effectively by currently registered soil fumigants $(11,46,52)$. Although seed treatment and in-furrow fungicide applications have not been successful at reducing black dot incidence or increasing yield in infested soil, foliar fungicide applications of the QoI fungicide azoxystrobin have proven effective in reducing black dot severity on stems and progeny tubers and increasing yield in the Columbia Basin of the United States $(5,28)$. Long-term survival of the pathogen in the soil, limited number of useful fungicides, a long latent period, a wide host range, varying and unpredictable effects of the disease, and confusion regarding disease etiology illustrate why effective control of black dot can be difficult.

A more complete understanding of disease epidemiology and etiology is needed 
to develop successful strategies for effective management of black dot of potato. The pathogen typically is introduced into noninfested soils via contaminated seed tubers, becomes established on the currentseason crop, and subsequently builds up in the soil on infected plant debris $(3,24,38)$. Soilborne inoculum may infect tubers, stolons, roots, and below ground stems $(38,50,51)$. The airborne phase of $C$. coccodes also can cause above ground stem and foliar infections via windblown inoculum originating from the soil, debris of previously infected plants, or currentseason foliar infections, often exacerbated by wounds caused by windblown soil $(3,21,23,27)$. Although considerable research has been performed comparing the effects of some inoculum sources, this research has not taken into account all potential infection sites and the importance, frequency, and timing of both above and below ground host tissue colonization $(1,6,11,21,27,28,38,39)$. Additionally, much of the early research was performed before differences in aggressiveness were characterized among vegetative compatibility groups (VCGs) $(2,19,31,32,34)$. As a result, there are gaps in knowledge concerning the influence, significance, and relative importance of individual or combinations of infection courts upon pathogen colonization and disease development in various host tissues.

Yield losses are known to occur as a result of $C$. coccodes infections $(3,21,27,50)$ but the relationship among disease severity, particularly with infection of specific host tissues, inoculation and/or infestation sites, the extent of these losses, and the interactions among these factors has not been investigated. The objectives of this research were to determine infection frequency of $C$. coccodes in specific plant tissues as affected by the site of inoculation and/or infestation and to determine the effects of such infections on black dot disease severity as well as yield and market value of the potato crop.

\section{MATERIALS AND METHODS}

Field trials. Field trials were conducted in 2003 and 2004 at the Northern Plains Potato Growers Association Irrigated Research Site in central North Dakota. The plot area in 2003 had been pasture land with no previous potato crop but, in 2004, the experiment was the second crop of potato in 3 years. The same trial also was conducted both years in commercial potato fields in west-central Minnesota which previously had been cropped to potato and were presumed to have indigenous levels of the black dot fungus. Trials were planted on 24 April and 29 May 2003 and 15 and 29 April 2004 in Minnesota and North Dakota, respectively. Certified seed tubers of cv. Russet Burbank were used in all four site-years, with the same lot used at both sites in a given year. The trials were managed using standard agronomic practices employed in each region. Fungicides, including chlorothalonil, ethylenebisdithiocarbamates, and fluazinam, were applied to the entire trial as a foliar spray to prevent late blight (Phytophthora infestans, (Mont.) de Bary) and to minimize development of early blight (A. solani). All trials were conducted using overhead irrigation and water was applied at intervals necessary to meet the evapotranspirational demands of the crop. Treatments consisting of four-row blocks were arranged in a randomized complete block design with four replications. The distance between rows was $0.91 \mathrm{~m}$, in-row seed tuber spacing was $0.3 \mathrm{~m}$, and row length was 12.2 and $13.7 \mathrm{~m}$ in 2003 and 2004, respectively.

Quantification of $C$. coccodes in soil. The indigenous level of $C$. coccodes in the soil each year at the central Minnesota site was quantified using dilution plating techniques as previously described (10), with the following modifications. Soil cores were removed at $0-$ to $20-\mathrm{cm}$ depths in a grid pattern (equidistance within the trial border), air dried and ground before being combined, and mixed thoroughly. In total, five 5- $\mu \mathrm{g}$ subsamples each of nondiluted and diluted (1:10 with sterile soil) cores were evenly dispersed onto Sorenson's NP-10 semiselective medium (16). Plates were incubated at $25 \pm 2^{\circ} \mathrm{C}$ for 14 days in the dark, soil particles were washed from the plates under running tap water, and colonies were counted using a stereomicroscope at $\times 65$ magnification.

C. coccodes inoculations. Eight isolates of $C$. coccodes collected from tubers, stems, roots, and stolons of commercial potato plants from across the United States were used to infest soil and inoculate seed tubers and foliage for each of four siteyears. In 2003, VCG designation was not known prior to performing the trial and, therefore, each $C$. coccodes VCG is not equally represented. Subsequent testing revealed that, among these eight isolates, two belonged to VCG1, two to VCG2, one to VCG5, and three to VCG6 (19). In 2004, isolates were specifically chosen representing VCG1 to -5: two isolates each of VCG1, 2, and 5 and one each of VCG3 and 4. In either case, each VCG was equally represented in the inoculum mixture; that is, twice the volume was added for each of the single isolates of VCG3 and -4 compared with the two isolates which were used for each of the other VCGs.

The importance of inoculation and/or infestation site was examined in a similar manner at all four site-years. Soil infestations, seed tuber, and foliar inoculations were performed individually and in every combination thereof, resulting in eight treatments, including a noninoculated and noninfested control. In the Minnesota 2003 trial, soil was infested with $C$. coccodescolonized rye seed (34). C. coccodes was grown on solid $10 \%$ clarified V8 juice
(CV8) medium (26) for 7 to 9 days in the dark at $25 \pm 2{ }^{\circ} \mathrm{C}$. Conidia and microsclerotia were scraped from cultures in sterile water and used to inoculate sterile rye seed. The rye was incubated in the dark at $25 \pm 2{ }^{\circ} \mathrm{C}$ for 4 weeks, air dried for 6 days, and subsequently placed in furrow at planting (IFAP) at a rate of $1.9 \mathrm{~g} / \mathrm{m}$. In the remaining three site-years, a $C$. coccodesinfested agar slurry was utilized to inoculate the soil. Isolates of $C$. coccodes were grown on CV8 for 2 to 3 weeks in the dark at $25 \pm 2{ }^{\circ} \mathrm{C}$. Agar cultures were homogenized in a blender and the microsclerotial concentration of each isolate was standardized to $10^{2} \mathrm{CFU} / \mathrm{ml}$. In 2003 in North Dakota, 4 liters of microsclerotia-agar suspension was mixed with 22 liters of vermiculite and applied IFAP at a rate of $164 \mathrm{ml} / \mathrm{m}$ of row. At both sites in 2004, the ensuing fungal slurry was applied directly to the field at a rate of $80 \mathrm{ml} / \mathrm{m}^{2}$ and tilled into the soil at a depth of 7.5 to $10.0 \mathrm{~cm}$ prior to planting.

Inoculum applied to seed tubers was prepared by growing isolates in 10\% CV8 liquid medium for 2 to 3 weeks. Fungal cultures were centrifuged at 5,000 rpm for 5 to $7 \mathrm{~min}$ and resuspended to an adjusted concentration of $10^{2}$ spores $/ \mathrm{ml}$ in a $0.25 \%$ gelatin solution to aid in spore adhesion and prevent desiccation. This suspension was sprayed onto suberized seed tubers until each tuber was coated (approximately $60 \mathrm{ml}$ per $450 \mathrm{~g}$ ). Noninoculated tubers were sprayed with a sterile solution of $0.25 \%$ gelatin. The tubers were air dried for 5 to $10 \mathrm{~min}$, placed in paper bags, and stored at $12 \pm 2{ }^{\circ} \mathrm{C}$ and 80 to $85 \%$ relative humidity (RH) for no longer than $24 \mathrm{~h}$ prior to planting. Foliar inoculations were conducted using a microsclerotial suspension prepared utilizing the same procedure as was described for soil inoculations in 2004. At 6 to 8 weeks after planting, the basal portion of plants in each row of the four-row plot, for applicable treatments, were sandblasted with silica sand at 245 $\mathrm{kPa}$ of pressure to create wounds for infection (23). A $10^{2}$ microsclerotia/ml suspension at $15 \mathrm{ml} / \mathrm{m}$ was applied to the resulting wounded portion of the canopy using a hand sprayer at $137 \mathrm{kPa}$ of pressure.

Tissue colonization. In all four siteyears, the frequency of colonization of $C$. coccodes was determined throughout the growing season by destructively sampling five plants from each treatment-replication combination at approximately 7-day intervals. The process was initiated 7 days post emergence and continued for 12 weeks in 2003 and 14 days preemergence and continued for 16 weeks in 2004. Three stems per hill (stems originating from a single seed tuber) were assayed on each sampling date by excising a 2- to 3-mm stem segment approximately $10 \mathrm{~cm}$ above and below the soil line. A single stolon and root segment, 5 to $7 \mathrm{~mm}$ in length, also was collected from each stem. In total, 46,080 
and 61,440 isolations for $C$. coccodes were made in 2003 and 2004, respectively. All tissue samples were placed onto culture plates containing solid Sorenson's NP-10 medium. Cultures were examined for the presence of $C$. coccodes after 3 to 4 weeks of incubation at $25 \pm 2{ }^{\circ} \mathrm{C}$ in the dark. The number of infections per tissue segment was recorded and infection frequency was expressed as percentage per stem. The area under the colonization progress curve (AUCPC) was calculated using weekly colonization data (44):

$$
\mathrm{AUCPC}=\sum_{i=1}^{n}\left[\left(W_{i+1}+W_{i}\right) / 2\right]\left(t_{i+1}-t_{i}\right)
$$

where $W_{i}=$ percentage of $C$. coccodes colonization at the $i$ th observation, $t_{i}=$ time in days at the $i$ th observation, and $n=$ total number of observations. AUCPC values were standardized to enable comparisons among site-years. Standardization was achieved by dividing the AUCPC values for each treatment of the replicated trials from each site-year by the total area of the graph, resulting in relative area under the colonization progress curve (RAUCPC).

Presumptive VCG analysis. Monoconidial isolates collected from all tissues and treatments at both sites in 2004 were selected for presumptive VCG analysis using amplified fragment length polymorphism (AFLP) markers (19). Sections of $C$. coccodes grown from tissues sampled at week $1,2,3,7$, and 8 were transferred to solid media containing $1.5 \%$ agar for hyphal tip or monoconidial isolation by micromanipulation. Permanent cultures were established on silica gel crystals stored at $-80^{\circ} \mathrm{C}$ in a $7.5 \%$ skim milk solution using microsclerotia scraped from homogeneous cultures of $C$. coccodes grown on CV8 medium amended with ampicillin at $50 \mathrm{mg} / \mathrm{ml}$ for 5 to 7 days (45).

Disease incidence. Black dot incidence on stems was assessed visually throughout the growing season. The number of stems in the center two rows of each four-row plot was recorded approximately 3 weeks after emergence. Incidence of black dot infection was assessed by determining the number of infected, wilted, or dead stems with obvious microsclerotial formation characteristic of $C$. coccodes commencing 62 to 115 days after planting (DAP) and continuing for 1 to 3 and 5 to 11 weeks in 2003 and 2004, respectively. Incidence was expressed as the percentage of stems exhibiting black dot disease symptoms.

Assessment of tuber yield and quality. The center two rows of each replicated treatment, $9.1 \mathrm{~m}$ in length at all four siteyears after destructive sampling was completed, were harvested between 125 and 160 DAP. Total yield and United States Department of Agriculture grade data were collected at the end of each growing season for each treatment. In 2004, French fry color and quality ratings also were per- formed on 25 randomly selected tubers per replication.

Statistical analysis. Two-factor analyses of variance (ANOVA) were performed on RAUCPC generated from in vitro tissue assays within each site-year using Proc GLM of SAS (version 9.1; SAS Institute, Cary, NC) with tissue type assayed and inoculation and/or infestation site as main effects. One-way ANOVAs were performed on black dot stem incidence as well as yield grade and processing data, when applicable, across each site year. In all instances, means were differentiated using Fisher's protected least significant difference (LSD) test ( $\alpha=0.05)$. Pearson's correlation was utilized to compare all combinations of $C$. coccodes colonization at the point in the growing season when frequency was approximately 40 to $50 \%$ at each site-year, black dot stem incidence at the final data collection date at each of the four site-years, and total yield. Then, $\chi^{2}$ tests of homogeneity were performed to evaluate the frequency of presumptive VCG recovery across sites (Minnesota and North Dakota), tissues (above and below ground stems, roots, and stolons) and weeks $(1,2,3,7$, and 8) during which $C$. coccodes isolates were obtained, as well as across all eight treatments $(\alpha=0.05)$. Fisher's exact tests were performed when underlying assumptions of the $\chi^{2}$ test were not met $(\alpha=0.05)$.

\section{RESULTS}

Quantification of $C$. coccodes in soil. In Minnesota in 2003, the indigenous $C$. coccodes population was 69 propagules per gram (ppg) dry weight of soil and, in 2004, the population was less than $1 \mathrm{ppg}$ dry weight. Levels of indigenous $C$. coccodes in the soil were not determined for either year at the North Dakota site because it was a newly developed potato research site.

C. coccodes tissue colonization. $C$. coccodes was detected in stems of potato plants at the first sampling date in all four site-years, including 14 days prior to emergence at both sites in 2004. The progression of $C$. coccodes colonization was variable, in some cases substantially, in noninoculated and noninfested plants among the four site-years when this study was performed (Fig. 1). At the North Dakota site in 2003, the frequency of colonization remained relatively low and unchanged until the last three collection dates of the season. Similar trends were observed at this site in 2004 but $C$. coccodes colonization frequencies began to increase earlier and were higher at the end of the growing season compared with 2003. $C$. coccodes colonization frequency was highest and progressed more rapidly in Minnesota in 2003 when compared with the other three site-years. At this site, $C$. coccodes colonization of noninoculated and noninfested plants was nearly $40 \%$ at 28 days after emergence (DAE) and exceeded $80 \%$ at 49 DAE compared with between nearly 0 and $50 \%$ during that same time period in the other three siteyears. Colonization by $C$. coccodes at the Minnesota site in 2004 was similar to that of the North Dakota site that same year.

A significant interaction was observed between the main effects of inoculation and/or infestation site and tissue sampled in colonization rate as expressed by the RAUCPC in the 2004 North Dakota trial $(P<0.0001)$ but not in the 2003 North Dakota trial $(P=0.065)$ or the Minnesota trial in $2003(P=0.748)$ and $2004(P=$ $0.998)$. The interaction at the 2004 North

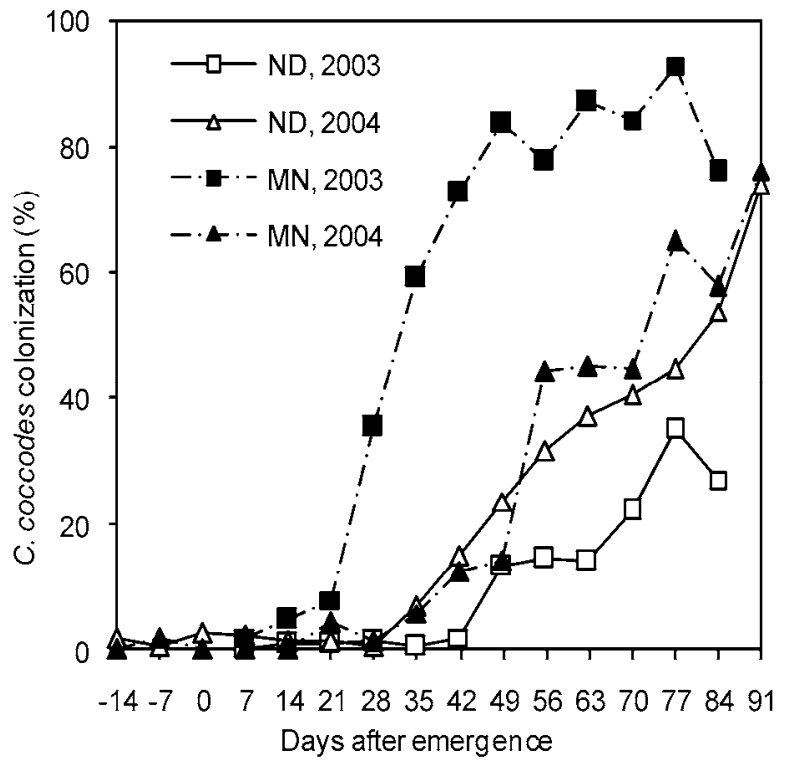

Fig. 1. Percentage of Colletotrichum coccodes colonization assayed in vivo from tissue of noninoculated potato plants grown in field trials performed in North Dakota (ND) and Minnesota (MN) in 2003 and 2004. Colonization frequency represents the mean of above and below ground stem, root, and stolon tissue. 
Dakota trial was due, in part, to those treatments with inoculated seed tubers having higher $C$. coccodes colonization frequencies of roots than stolons while those treatments without seed tuber inoculation had higher colonization frequencies of stolons compared with roots (data not shown). There also were significant differences among the main effects of inoculation and/or infestation site as well as tissues sampled in all four site-years (Tables 1 and 2). C. coccodes colonization frequencies measured by RAUCPC were significantly different in all site-years among inoculation and/or infestation treatcolonization were observed in both years in North Dakota. At this site, RAUCPC values of noninoculated and noninfested controls were significantly lower than nearly all inoculated and/or infested treatments. Treatments with multiple inoculation and/or infestation sites also tended to have significantly higher RAUCPC values than those treatments with single inoculation or infestation events. Plants from soil infested + seed tuber + foliar inoculatedtreatments displayed the highest level of colonization, although not always significantly so. When comparing multiple inoculation and infestation events, plants from treatments in which seed tubers were inoculated, in combination with either soil infestation or foliar inoculation, tended to have higher colonization levels compared with the combination of soil infestation and foliar inoculation. Again, these differments (Table 1). Similar patterns of tissue

ences were not always significant. In Minnesota in 2003, although differences among RAUCPC values were significant, the range of these values was small (Table 1). The noninoculated and noninfested control did not display the lowest RAUCPC values, and additional inoculation and/or infestation events did not consistently increase colonization as was observed in North Dakota, presumably due to high indigenous soil populations present that year (69 ppg of soil). However, at this site in 2004, with relatively low indigenous soil populations $(<1 \mathrm{ppg}$ of soil), trends were similar to those observed in North Dakota.

Across site-years, colonization was detected at the first sampling date but progressed more quickly in above and below ground stem tissue than in roots and stolons, resulting in significantly higher RAUCPC values for these tissues (Fig. 2A-D; Table 2). In North Dakota in 2003, below ground stem tissue was infected at significantly higher frequencies than above ground stem tissue while colonization frequencies of above and below ground stems were the same in 2004 at this site (Fig. 2A and B; Table 2). In both years in North Dakota, colonization of stolon tissue was significantly greater than that of root tissue (Fig. 2A and B; Table 2). In Minnesota in 2003, differences in colonization were significantly different among all tissues, with above ground tissue colonization greatest, followed by below ground stems, stolons, and roots (Fig. 2C; Table 2). In 2004 at this same site, there was no

Table 1. Relative area under the Colletotrichum coccodes colonization progress curve among inoculation and/or infestation sites across all potato tissues sampled ${ }^{\mathrm{z}}$

\begin{tabular}{lcccccc}
\hline & \multicolumn{2}{c}{ North Dakota } & & \multicolumn{2}{c}{ Minnesota } \\
\cline { 2 - 3 } \cline { 5 - 6 } Site of inoculation and/or infestation & $\mathbf{2 0 0 3}$ & $\mathbf{2 0 0 4}$ & & $\mathbf{2 0 0 3}$ & $\mathbf{2 0 0 4}$ \\
\hline No inoculation and infestation & $0.10 \mathrm{f}$ & $0.20 \mathrm{f}$ & & $0.57 \mathrm{bc}$ & $0.22 \mathrm{~d}$ \\
Seed tuber inoculation & $0.11 \mathrm{ef}$ & $0.25 \mathrm{bc}$ & & $0.59 \mathrm{ab}$ & $0.25 \mathrm{bcd}$ \\
Soil infestation & $0.12 \mathrm{de}$ & $0.21 \mathrm{ef}$ & & $0.57 \mathrm{bc}$ & $0.24 \mathrm{~cd}$ \\
Foliar inoculation & $0.15 \mathrm{bc}$ & $0.22 \mathrm{de}$ & & $0.58 \mathrm{~b}$ & $0.27 \mathrm{bc}$ \\
Soil infestation + seed tuber inoculation & $0.14 \mathrm{bc}$ & $0.27 \mathrm{ab}$ & & $0.59 \mathrm{ab}$ & $0.26 \mathrm{bc}$ \\
Seed tuber + foliar inoculation & $0.16 \mathrm{bc}$ & $0.28 \mathrm{a}$ & & $0.62 \mathrm{a}$ & $0.31 \mathrm{a}$ \\
Soil infestation + foliar inoculation & $0.13 \mathrm{~cd}$ & $0.24 \mathrm{~cd}$ & & $0.57 \mathrm{bc}$ & $0.28 \mathrm{ab}$ \\
Soil infestation + seed tuber + foliar inoculation & $0.19 \mathrm{a}$ & $0.28 \mathrm{a}$ & & $0.55 \mathrm{c}$ & $0.31 \mathrm{a}$ \\
$P$ value & $<0.0001$ & $<0.0001$ & & $<0.0001$ & $<0.0001$ \\
\hline
\end{tabular}

${ }^{\mathrm{z}}$ Values in a column followed by the same letter are not statistically different based on Fisher's protected least significant difference $(\alpha=0.05)$. $P$ value represents the probability of observing a greater value in the $F$ test.

Table 2. Relative area under the Colletotrichum coccodes colonization progress curve among potato tissues sampled across all noninoculated and noninfested and inoculated and/or infested treatments ${ }^{\mathrm{z}}$

\begin{tabular}{lccccc}
\hline & \multicolumn{2}{c}{ North Dakota } & & \multicolumn{2}{c}{ Minnesota } \\
\cline { 2 - 3 } \cline { 5 - 6 } Tissue & $\mathbf{2 0 0 3}$ & $\mathbf{2 0 0 4}$ & & $\mathbf{2 0 0 3}$ & $\mathbf{2 0 0 4}$ \\
\hline Above ground stem & $0.16 \mathrm{~b}$ & $0.34 \mathrm{a}$ & & $0.75 \mathrm{a}$ & $0.28 \mathrm{a}$ \\
Below ground stem & $0.20 \mathrm{a}$ & $0.34 \mathrm{a}$ & & $0.63 \mathrm{~b}$ & $0.30 \mathrm{a}$ \\
Roots & $0.07 \mathrm{~d}$ & $0.13 \mathrm{c}$ & & $0.42 \mathrm{~d}$ & $0.25 \mathrm{~b}$ \\
Stolons & $0.12 \mathrm{c}$ & $0.15 \mathrm{~b}$ & & $0.52 \mathrm{c}$ & $0.24 \mathrm{~b}$ \\
$P$ value & $<0.0001$ & $<0.0001$ & & $<0.0001$ & $<0.0001$ \\
\hline
\end{tabular}

${ }^{\mathrm{z}}$ Values in a column followed by the same letter are not statistically different based on Fisher's protected least significant difference $(\alpha=0.05)$. $P$ value represents the probability of observing a greater value in the $F$ test. significant difference between above and below ground stem colonization or between roots and stolons; however, stems were colonized at significantly higher frequencies than roots and stolons (Fig. 2D; Table 2).

Presumptive VCG analysis. In total, 91 $C$. coccodes isolates collected from both sites in 2004 were evaluated via AFLP analysis to determine a presumptive VCG (19). AFLP analysis is not able to differentiate the uncommon VCG4 from other VCGs; therefore, only VCG1, $-2,-3$, and 5 were detected among isolates collected from sample plants. Across all isolates, the frequency of recovery was not evenly distributed among these four VCGs. Overall, the frequency of recovery of isolates from VCG2 and -5 (28 and 40\%, respectively) was substantially greater than that of VCG1 and -3 (10 and 13\%, respectively). However, $\chi^{2}$ and Fisher's exact analyses revealed that there was no significant difference in the frequency of recovery of each VCG across the two sites $(P=$ $0.1371 ; P=0.1106)$, across the 5 weeks isolates were characterized $(P=0.1970 ; P$ $=0.3369)$, or among above and below ground stems, stolons, or roots $(P=$ $0.8988 ; P=0.9719)$. A significant difference was observed in the frequency of isolates recovered from each of the eight treatments using both analyses $(P=$ 0.0008; $P=0.0001$ ) (Fig. 3A-D). Interestingly, although the number of isolates recovered per treatment-VCG combination was low, the noninoculated and noninfested control was the only treatment from which no isolates belonging to VGC5 were recovered (Fig. 3D). The mean of isolates belonging to VCG5 recovered from treatments containing inoculated seed tubers, alone or in any combination, ranged from 46 to $73 \%$, whereas those with infested soil and inoculated foliage alone had a mean of 17 and $9 \%$, respectively. Similarly, the treatment containing the combination of soil infestation and foliar inoculation yielded $29 \%$ of isolates belonging to VCG5. The inverse was true for isolates belonging to VCG2 (Fig. 3B). The frequency of $C$. coccodes isolates belonging to VCG2 recovered from treatments with inoculated seed tubers was much lower (mean of 13\%) than the frequency of this VCG recovered from infested soil or foliar inoculated treatments at 67 and $82 \%$, respectively. The combination of soil infestation and foliar inoculation yielded $71 \%$ of isolates belonging to VCG2. Isolates belonging to VCG1 and -3 represented less than $25 \%$ of the total for any individual treatment (Fig. 3A and C).

Black dot disease incidence. Black dot disease incidence on stems tended to be significantly different only among inoculation and/or infestation treatments when disease incidence was high (Fig. 4A-D). In central North Dakota in 2003, black dot disease incidence ranged from 9.6 to 
$18.5 \%$ at the final data collection date 113 DAP (Fig. 4A). Although nearly twice as much black dot was observed in soil infested + seed tuber + foliar-inoculated plots compared with noninoculated and noninfested plots, there was no significant difference among treatments at any of the four data collection dates. In 2004 at this site, a significant difference was observed among treatments at the last data collection date 138 DAP, with disease incidence ranging from 37.9 to $55.4 \%$ (Fig. 4B), substantially higher than that observed in 2003. The noninoculated and noninfested control displayed the least amount of black dot stem incidence, although not significantly different from all inoculated and/or infested treatments.

In the 2003 Minnesota trial, a significant difference was observed among treatments in black dot stem incidence at both data collection dates. Disease incidence ranged from 24.9 to $47.2 \%$ at the last data collection date 119 DAP, and the noninoculated and noninfested treatment had significantly lower disease incidence than inoculated and/or infested treatments with the exception of seed tuber inoculation (Fig. 4C). There were no significant differences observed among any of the inoculated and/or infested treatments (Fig. 4C). At this site in 2004, no significant differences were observed among treatments at any data collection date, and black dot disease incidence was low, ranging from 7.7 to $14.7 \%$ at the last data collection date at 139 DAP, similar to what was observed in North Dakota in 2003 (Fig. 4D).

Yield and tuber quality assessments. No significant differences in total yield were observed among sites of inoculation and/or infestation in either year at the North Dakota site (Table 3). A significant difference in total yield was observed only among site of inoculation and/or infestation at the 2003 Minnesota site. Although the noninoculated and noninfested treatment did result in the highest total yield, these differences were significant only when compared with treatments with more than one site of inoculation and/or infestation, with the exception of the soil infested + seed tuber + foliar-inoculated treatment. However, differences in total yield were not significantly different in Minnesota in 2004, and no significant differences were observed in marketable yield, including tuber size and quality, or French fry quality among the four site-years (data not shown).

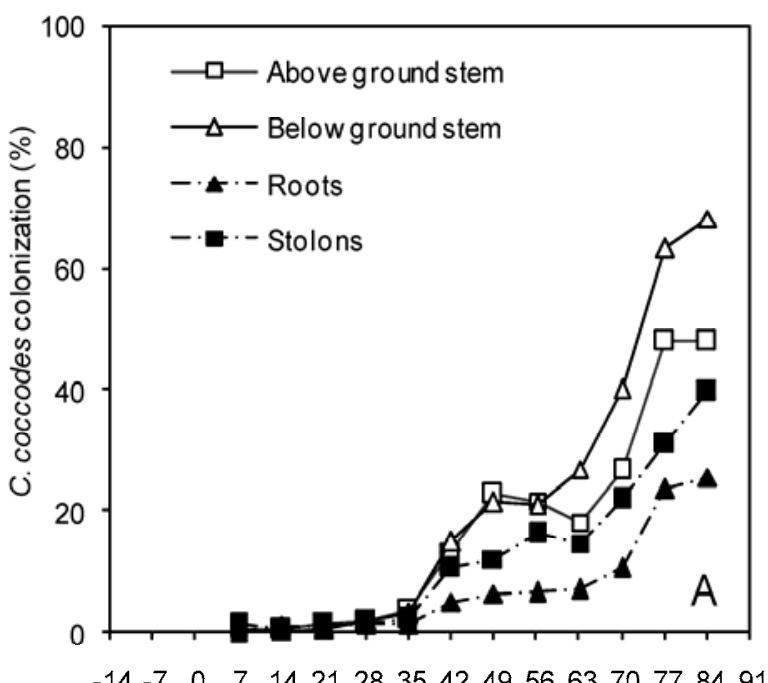

Days after emergence

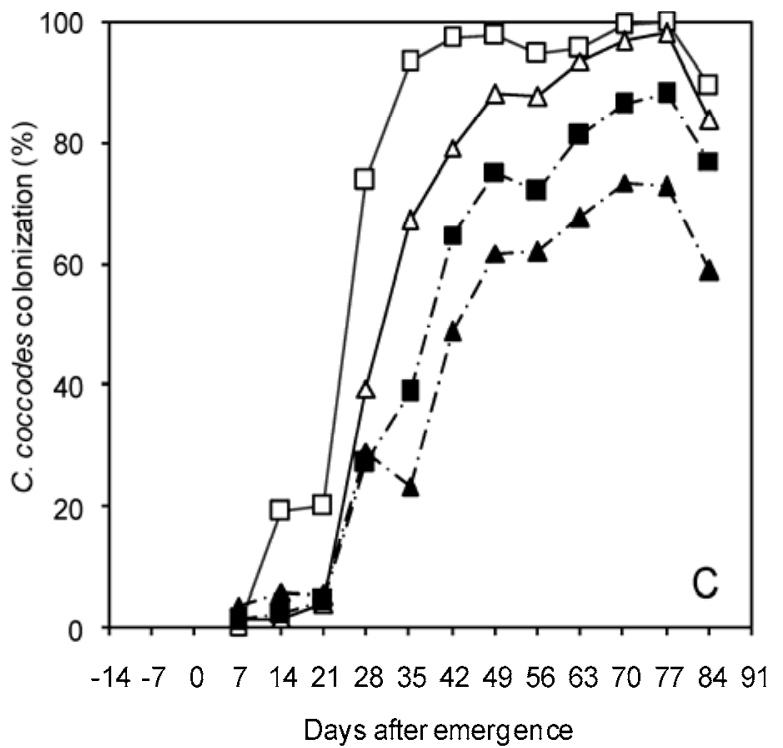

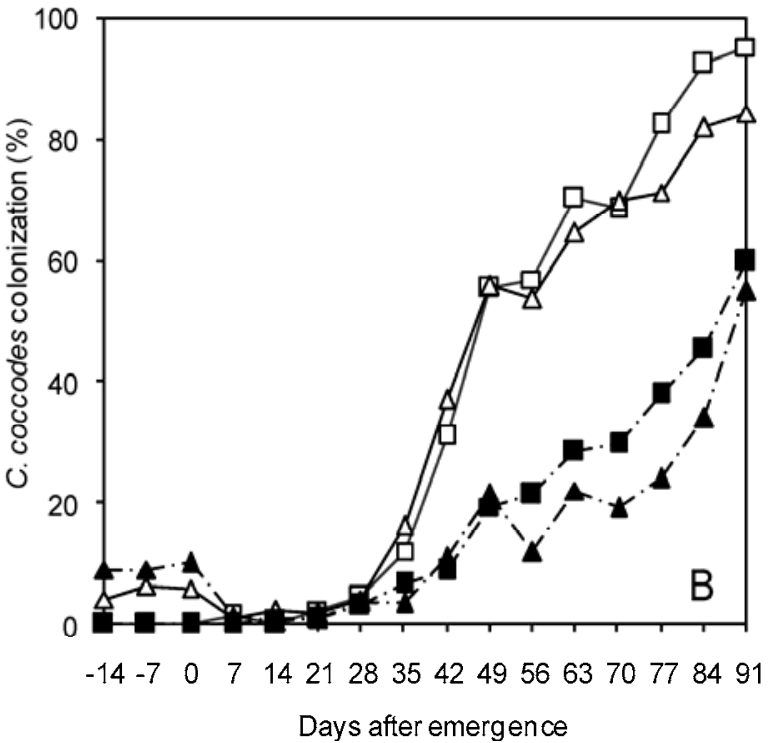

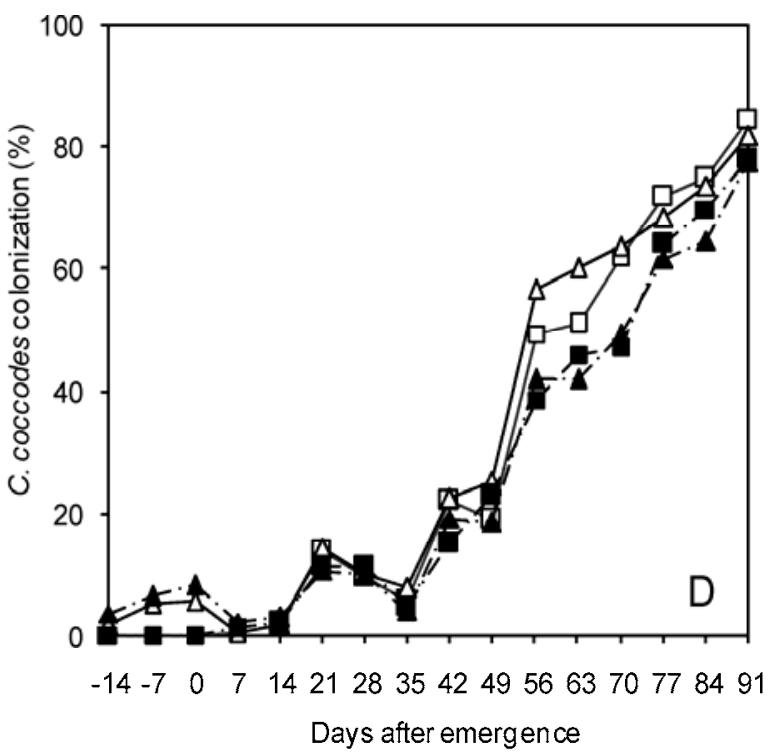

Fig. 2. Percentage of Colletotrichum coccodes colonization assayed in vivo from above and below ground stem, root, and stolon tissue of potato plants grown in field trials performed in $\mathbf{A}$ and $\mathbf{B}$, North Dakota and $\mathbf{C}$ and D, Minnesota in A and $\mathbf{C}, 2003$ and $\mathbf{B}$ and D, 2004. Colonization frequency represents the mean of all plants in noninoculated and noninfested and inoculated and/or infested treatments. 
The relationship among black dot stem incidence at the last data collection date, C. coccodes colonization, and total yield was variable among site-years, according to Pearson's correlation analyses (Table 4). A consistent and significant correlation was observed among all three comparisons only at the 2003 Minnesota site. At this site, black dot stem incidence at 122 DAP and colonization frequency at $60 \mathrm{DAP}(r=$ 0.83; $P=0.012)$, black dot stem incidence and total yield $(r=-0.88 ; P=0.004)$, and colonization frequency and yield $(r=$ $-0.76 ; P=0.030$ ) all had a highly significant relationship. A significant negative relationship was also observed between $C$. coccodes colonization frequency 96 DAP and total yield $(r=-0.64 ; P=0.087)$ at the North Dakota 2003 site as well as black dot stem incidence at $138 \mathrm{DAP}$ and $C$. coccodes colonization frequency 89 DAP $(r=0.84 ; P=0.010)$ at the North Dakota 2004 site. Although some trends were observed among these variables at other site-years, none were significant (Table 4).

\section{DISCUSSION}

Although several previous research studies have examined $C$. coccodes colonization and the development of black dot symptoms in potato $(1,6,7,22,31,39,50,51)$, the results reported here provide a comprehensive comparison of colonization, disease development, and yield. Some of the previous studies concentrated on the development of disease without evaluating the frequency of $C$. coccodes colonization $(1,39)$. Research conducted with soil infestations of $C$. coccodes on two cultivars commonly grown in the United Kingdom demonstrated that black dot symptoms appeared at a high rate in root tissue (60 to $90 \%$ ) at the first assessment date 5 weeks after planting regardless of inoculum level (low versus high) but little or no disease was visible on below ground stems (39). Similar research focused on tuber-borne inoculum determined that symptoms on roots and stolons could be detected within 1 week after inoculating seed tubers, around the time of emergence, whereas symptoms on stems did not appear until approximately 7 to 10 weeks after inoculation (1).

Among studies that have examined $C$. coccodes colonization of host tissue, in plants assayed from 37 commercial potato fields in Idaho, colonization of both basal and apical stem sections by $C$. coccodes was correlated with the amount of patho-
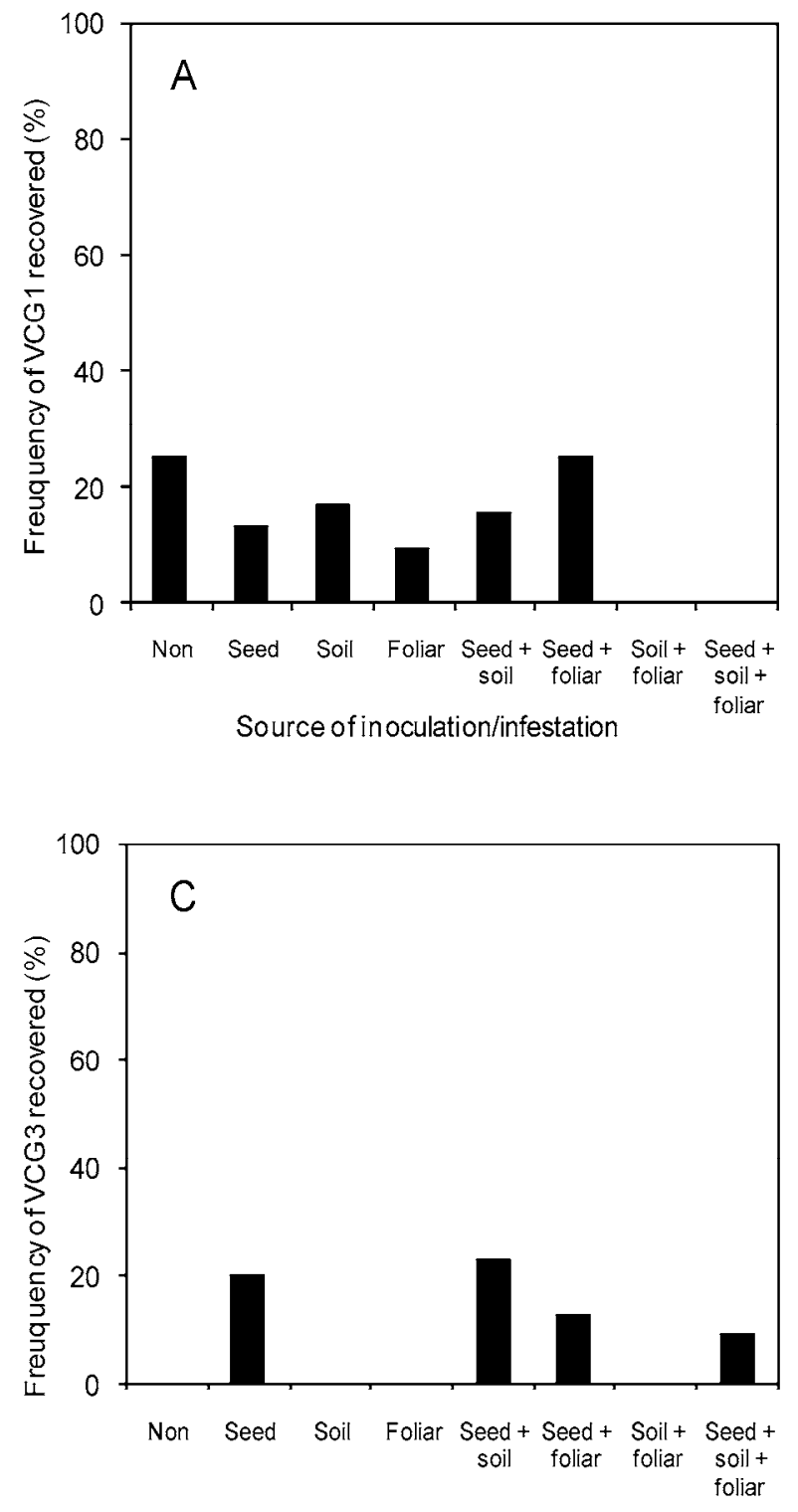

Source of in oculation/infestation
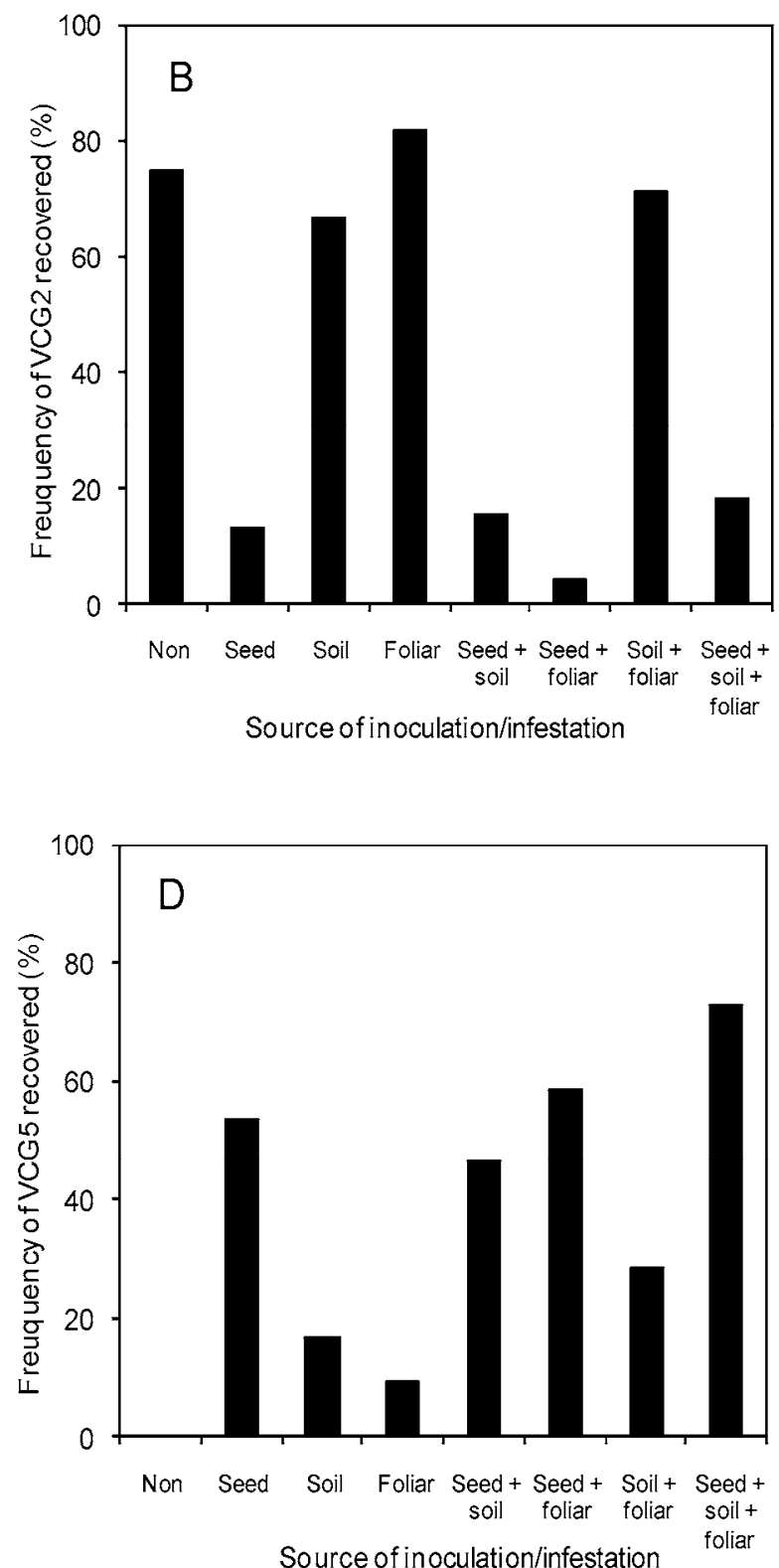

Fig. 3. Frequency of recovery of Colletotrichum coccodes isolates belonging to A, vegetative compatibility group (VCG)1; B, VCG2; C, VCG3; and D, VCG5 among sources of inoculation and/or infestation. Isolates were recovered from potato plants produced in North Dakota and Minnesota trials in 2004 from above and below ground stem, root, and stolon samples taken at five sampling dates across the season. 
gen recovered from the soil (7). However, subsequent research determined that, under growth-chamber conditions, colonization by $C$. coccodes at the base of the stem was not affected by soil inoculum density (51). Research performed under commercial growing conditions in the Columbia Basin of central Washington reported that $C$. coccodes was isolated at the first sampling date, as early as 15 days after emergence in above ground stems, and later, 22 days after emergence, in below ground stems; however, a larger number of CFU typically were isolated from below ground stems on subsequent sampling dates (22). More recent research performed under greenhouse conditions by the same group determined that the pathogen moved more quickly downward from a single inoculation point on the above ground stem than toward the apex of the plant (31). Root and stolon tissue was not assayed in any of these studies. Under field trial conditions in Scotland, C. coccodes colonization of root tissue produced from disease-free micropropagated plants was similar to that in roots produced from both visually blemish-free and blemished seed tubers when evaluated early in the growing season but was substantially lower at later sampling dates (6). One study has evaluated $C$. coccodes colonization in roots as well as above and below ground stem tissue in inoculated plants under field conditions but did so only once during the growing season at 90 DAP (50). At that point, no differences in colonization frequency among these plant tissues were apparent across the five cultivars evaluated in five trials. To our knowledge, the studies reported here rep- resent the first attempt to evaluate colonization of potato tissue by $C$. coccodes using multiple inoculation and/or infestation sites and all affected tissues, including roots and stolons as well as above and below ground stems, across the entire growing season.

The results reported here illustrate a different picture of tissue colonization than previously has been described. Colonization of stem tissue by $C$. coccodes above and below ground was higher than the colonization frequency of stolons and roots at all four site-years of the study. This trend was true regardless of whether the infection originated from soil infestation, seed tubers, or foliar inoculation. This is in contrast to previous studies which have demonstrated that black dot disease symptoms can be detected first in root tissue
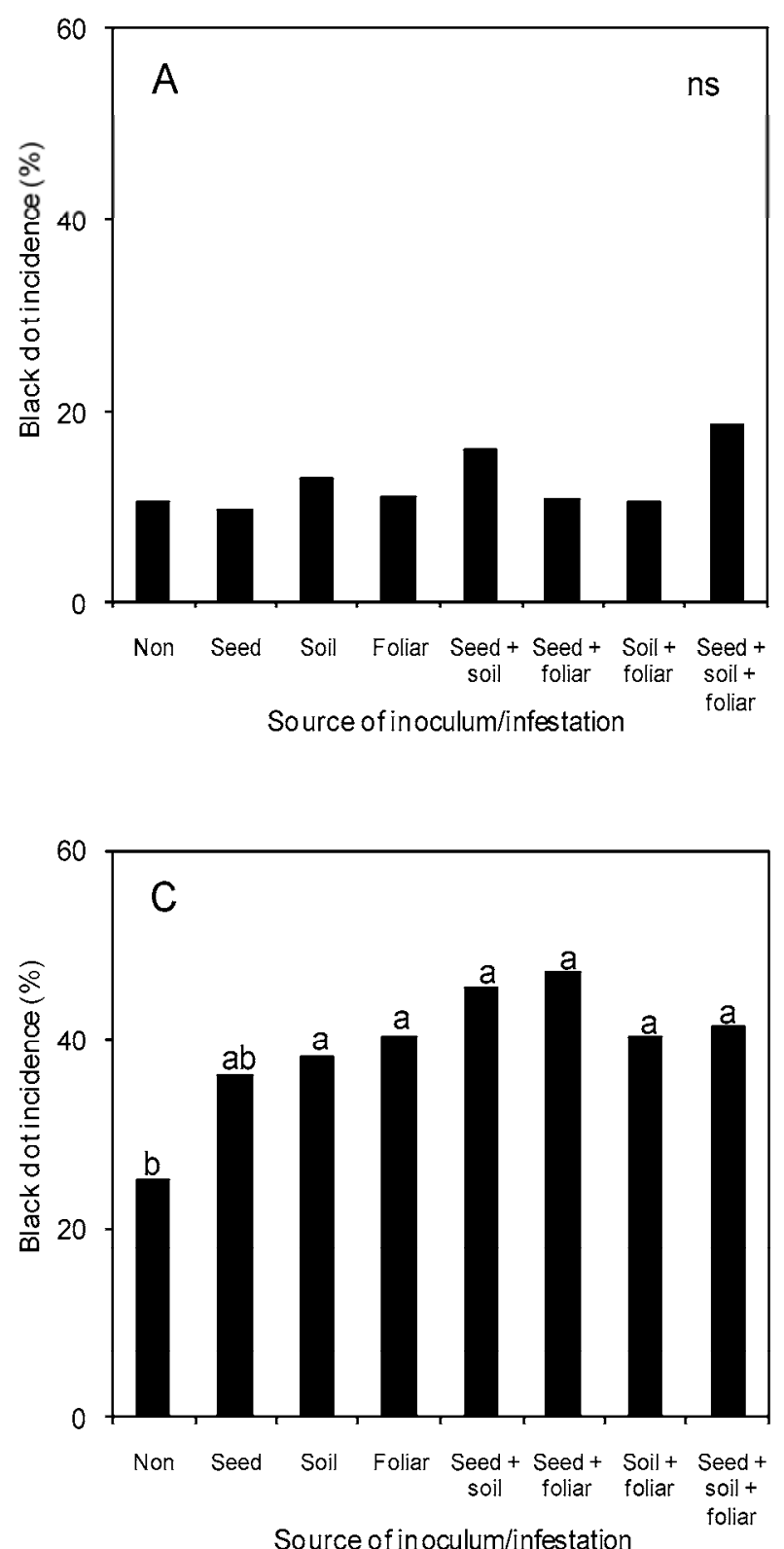
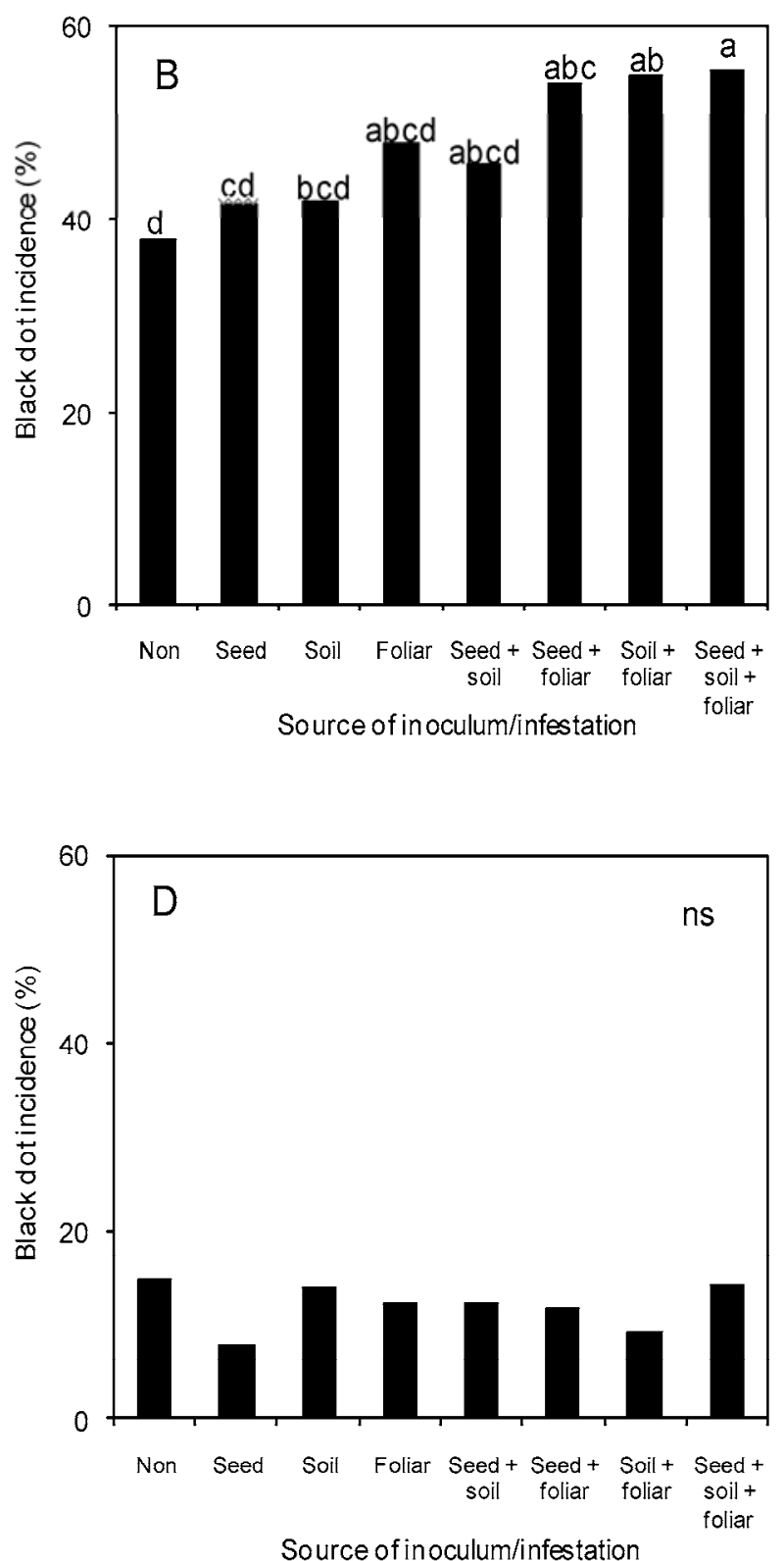

Fig. 4. Incidence of black dot symptoms in potato stems on the final data collection date for each trial: A, 113 days after planting (DAP) at the North Dakota 2003 trial; B, 138 DAP at the North Dakota 2004 trial; C, 119 DAP at the Minnesota 2003 trial; and D, 139 DAP at the Minnesota 2004 trial. Bars with the same letter are not statistically different based on Fisher's protected least significant difference $(\alpha=0.05)$. 
compared with other plant tissues evaluated $(1,39)$. Both of these studies evaluated symptom expression, and not tissue colonization of the fungus, the most likely reason for the discrepancies. It is commonly accepted that infections by $C$. coccodes remain latent for an extended time period, and this may be more evident in thicker stem tissue than in finer root and stolon tissue. Among the previous research which evaluated colonization, comparisons in timing of colonization were made only between above and below ground stems, and indicated that above ground stems were colonized approximately a week earlier than below ground stem tissue (22). In the first year of this study, colonization was detected in all tissues sampled at the Minnesota site and in above ground stems and stolons at the North Dakota site at the gence. Because the point at which initial infection had taken place presumably was missed, sampling was initiated earlier in the second year of the study. Again, $C$. coccodes stem colonization was detected at both sites in both below ground stems and roots approximately 14 days prior to emergence, which never has been reported previously. Also, colonization was recorded at the first sampling date in all tissues sampled in three of the four siteyears. The contrast in these results from previous studies might be attributed to first sampling date 14 days after emer-

differences in the levels of seed tuber inocula and soil infestation $(3,11,14,17)$, cultivar susceptibility $(1,27,48,50,51)$, or environmental factors $(38,46,50)$.

These studies also corroborate previous work indicating that soil infestations and foliar and seed tuber inoculations are all capable of initiating C. coccodes infections. Previous research conducted by inoculating foliage under greenhouse conditions found a correlation between leaf lesions and wilt, as well as wilt and yield for plants, but seed tuber inoculations or soil infestations were not evaluated (3). The effect of foliar inoculations and soil infestations have been investigated individually in the field and greenhouse $(27,50)$. Although some significant differences in stem death and wilting were observed between foliar and noninoculated plants under field conditions as well as between soil and noninfested plants in the greenhouse (27), greater stem colonization occurred with foliar inoculations compared with soil infestations under field conditions (50); however, these sources were not evaluated in the same trial and direct comparisons are not possible.

Previous studies which compared the effect of soil and seedborne inoculum indicated that soil inoculum may cause more black dot than seedborne inoculum $(11,28,29,39)$. Under field conditions in the United Kingdom, varying levels of

Table 3. Total yield (mT/ha) among Colletotrichum coccodes inoculation and/or infestation sources across all potato tissues sampled ${ }^{\mathrm{z}}$

\begin{tabular}{|c|c|c|c|c|}
\hline \multirow[b]{2}{*}{ Site of inoculation and/or infestation } & \multicolumn{2}{|c|}{ North Dakota } & \multicolumn{2}{|c|}{ Minnesota } \\
\hline & 2003 & 2004 & 2003 & 2004 \\
\hline No inoculation and infestation & 7.94 & 7.26 & $9.05 \mathrm{a}$ & 8.84 \\
\hline Seed tuber inoculation & 8.08 & 7.45 & $8.40 \mathrm{ab}$ & 9.33 \\
\hline Soil infestation & 7.98 & 7.78 & $8.65 \mathrm{ab}$ & 9.38 \\
\hline Foliar inoculation & 7.60 & 6.95 & $7.94 \mathrm{bc}$ & 9.16 \\
\hline Soil infestation + seed tuber inoculation & 8.16 & 7.09 & $7.99 \mathrm{bc}$ & 9.00 \\
\hline Seed tuber + foliar inoculation & 8.17 & 6.51 & $7.47 \mathrm{c}$ & 9.42 \\
\hline Soil infestation + foliar inoculation & 7.98 & 7.66 & $7.98 \mathrm{bc}$ & 9.21 \\
\hline Soil infestation + seed tuber + foliar inoculation & 7.86 & 7.46 & $8.35 \mathrm{ab}$ & 9.37 \\
\hline$P$ value & 0.895 & 0.064 & 0.012 & 0.847 \\
\hline
\end{tabular}

${ }^{z}$ Values in a column followed by the same letter are not statistically different based on Fisher's protected least significant difference $(\alpha=0.05)$. $P$ value represents the probability of observing a greater value in the $F$ test.

Table 4. Relationship between black dot stem incidence (Incidence), Colletotrichum coccodes colonization frequency (Frequency), and total yield of potato (Yield) as determined by Pearson's correlation coefficient

\begin{tabular}{lccccr}
\hline & \multicolumn{3}{c}{$\boldsymbol{r}^{\mathbf{y}}$} \\
\cline { 2 - 3 } \cline { 5 - 6 } \cline { 5 - 6 } Comparison parameters $^{\mathbf{z}}$ & \multicolumn{2}{c}{ North Dakota } & & \multicolumn{2}{c}{ Minnesota } \\
\cline { 2 - 3 } \cline { 5 - 6 } Incidence vs. Frequency & $\mathbf{2 0 0 3}$ & $\mathbf{2 0 0 4}$ & & $\mathbf{2 0 0 3}$ & $\mathbf{2 0 0 4}$ \\
Incidence vs. Yield & 0.04 & $0.84^{*}$ & & $0.83^{* *}$ & 0.38 \\
Frequency vs. Yield & -0.01 & -0.22 & & $-0.88^{* *}$ & -0.28 \\
\hline & $-0.64^{*}$ & -0.42 & & $-0.76^{* *}$ & 0.37 \\
\hline
\end{tabular}

${ }^{\mathrm{y}}$ Asterisks indicate Pearson correlation coefficients; $* *$ and $*=$ significant at the $\alpha=0.05$ and 0.10 levels, respectively; $n=8$.

${ }^{\mathrm{z}}$ Black dot stem incidence was evaluated at 113, 138, 122, and 139 days after planting for the North Dakota 2003 and 2004 and Minnesota 2003 and 2004 trials, respectively. C. coccodes colonization frequency was evaluated at 96, 89, 60, and 101 days after planting for the North Dakota 2003 and 2004 and Minnesota 2003 and 2004 trials, respectively. inoculum applied to seed tubers resulted in increases in black dot infection on stem bases and roots but not consistently across seed tuber disease levels and cultivars, whereas soil infestation more consistently increased black dot infection (39). Seed tuber and soilborne inoculum was investigated in individual field trials which did not allow for direct comparisons to be made, and no combination of the inoculation and/or infestation sources was evaluated (39). Also, under field conditions, soil infestation was reported to result in decreased yield and increased black dot incidence on progeny tubers compared with either light or severe seedborne pathogen levels (11) but no wilt severity or $C$. coccodes colonization levels were examined. More recently, where similar levels of natural soil infestations were present, progeny tubers from seed tubers with low levels of black dot displayed more black dot symptoms than tubers produced from seed tubers with higher levels of black dot (28). This indicates that soil inoculum may cause more infections in progeny tubers than seedborne inoculum. Finally, soil infestations performed in the greenhouse were determined to result in increased sclerotial development on roots and stems when compared with seedborne inoculum (29). However, differences in research methods as well as the type of data collected in the aforementioned research make comparisons between studies difficult. Therefore, gaps remain in our understanding of $C$. coccodes colonization of potato plants.

In all four site-years, sufficient indigenous inoculum was available to establish substantial disease levels in noninoculated and noninfested treatments. Despite this, at three of the four site-years, lower colonization frequency was observed in noninoculated and noninfested treatments compared with inoculated and/or infested treatments, indicating that the inoculations and/or infestations were effective in increasing black dot colonization to varying degrees. Levels of $C$. coccodes in the soil were evaluated prior to planting the trial in both years at the central Minnesota site. Although colonization frequencies were affected by inoculation and/or infestation in both years, no consistent trends were observed in 2003, likely due to the relatively high level of naturally occurring inoculum (approximately 69 ppg of soil). However, in 2004, when the indigenous soil inoculum was $<1 \mathrm{ppg}$, plants from noninoculated and noninfested treatments displayed the lowest levels of colonization, followed by plants from singleinoculation or -infestation and multipleinoculation and/or -infestation treatments, respectively. Interestingly, it is apparent from these data that inoculum potential $<1$ ppg of soil was sufficient to establish stem infections as high as $50 \%$ midway through the season, while higher levels of inocula present the previous year were effective in 
raising infection frequencies to nearly $95 \%$ at the same time in the growing season. Although levels of soilborne inoculum in naturally occurring infestations of $C$. coccodes and their relationship to disease development have not been examined in detail, increasing soilborne inoculum was reported to increase black dot disease severity, including foliar necrosis and chlorosis as well as sclerotial development on roots and stems, under greenhouse conditions (29). Also, among 37 potato fields in Idaho, the levels of $C$. coccodes in the soil were highly correlated with both basal and apical stem colonization (7). A later survey of Idaho potato fields confirmed these reports. C. coccodes levels ranged from 0.2 to $211 \mathrm{ppg}$ of soil and tuber tissue infection was highly correlated with the field soil inoculum levels (3). Soil infestation levels at the central Minnesota trial site in the present study fall within the range documented above.

Inconsistencies in the ability of $C$. coccodes to affect yield or cause disease are not unexpected and have been reported on numerous occasions with black dot greenhouse and field research $(3,7,21,22,27,28$, $39,43,46,49-52)$. Variable results in yield reduction were reported between field experiments performed over 2 years in Idaho when comparing cultivar reaction to foliar inoculations (27). A later study successfully demonstrated that $C$. coccodes infections significantly reduced yield under both greenhouse and field conditions and that these yield losses could be correlated to wilt, although asymptomatic $C$. coccodes infections also led to yield reductions (3). In field experiments examining soil infestations and seedborne inoculum on black dot development in two cultivars, significant reductions in total tuber yield were observed in only 1 year of this study, when the crop was planted with seed tubers severely infected with $C$. coccodes, even though plants were noticeably colonized by $C$. coccodes (39). Differences in tuber weight reductions were reported under greenhouse conditions when comparing foliar to root inoculations (2). In that study, root inoculations reduced tuber weights more than foliar inoculations but disease progression and colonization were not evaluated. In the current study, root colonization by $C$. coccodes generally lagged behind above ground infections; therefore, it is clear why yield reductions were not detected in most site years. In contrast, foliar inoculations decreased yield more than both seed tuber inoculation and soil infestation, although these differences were significant at only one site-year. This disparity is most likely due to the presence of natural inoculum, differences in inoculation methods, and environmental factors (which were controlled under greenhouse conditions), in addition to difficulties measuring yield reductions caused by this pathogen.
Differences in aggressiveness among VCGs of $C$. coccodes $(2,19,32,34)$ may play a role in these inconsistencies because most studies involving the impact of black dot on yield of potato were performed before vegetative compatibility was reported in this fungus. One recent research study has taken into account $C$. coccodes VCGs (29). Two isolates of VCG2 led to higher disease incidences when originating from soil than from seed tubers, whereas the opposite was true for a third isolate belonging to VCG1. These results support the findings reported here, in which higher frequencies of isolates of VCG2 were recovered from plants that had grown in infested soil when compared with those from inoculated seed tubers. Some of the past contradictory yield results also may be attributed to differences in cultivar susceptibility. Data generated in both field and greenhouse trials demonstrated that latermaturing cultivars are more likely to suffer yield reductions than earlier-maturing cultivars $(2,27)$. Also, recently reported results of colonization of control cultivars and breeding selections by $C$. coccodes grown in naturally infested soil indicated that differences among cultivars or selections exist and that these differences were significantly affected by environmental conditions (30). Although there are other examples of contradictory reports concerning the effect of $C$. coccodes on yield of potato, the aforementioned research results provide an ample illustration of the difficulties that lie in quantifying direct affects of this pathogen. The effects of black dot on yield reported here are consistent with the observations made in the several earlier studies. The Minnesota 2003 site was the only one to have significant yield loss compared with the noninoculated and noninfested control. At this site, the significant negative correlation between black dot incidence at the time of haulm desiccation on 22 August and yield in the latematuring cv. Russet Burbank may provide some indication of yield loss. A similar comparison was made with soil inoculum, C. coccodes colonization levels, and wilt on 23 August in previous research performed in Idaho (7). An association of this type potentially may act as a predictor of season-end black dot incidence and, ultimately, effect on tuber yield. These relationships clearly should be investigated in further studies.

C. coccodes still often is considered to be a weak pathogen, attacking plants following periods of stress or causing blemishes on tubers; however, results reported here and from similar work demonstrate that the picture is much broader. The effects of $C$. coccodes on yield and tuber quality ultimately will be tied to a variety of factors, such as inoculum potential, environmental conditions, cultural practices, cultivar, and pathogen VCG. Although black dot may not cause reductions in yield and tuber quality in all instances, C. coccodes remains a serious threat to commercial potato production and the seed potato industry, particularly in areas where Verticillium wilt is a concern and interactions between the two pathogens occur $(8,35,42,43,51)$. The data reported here may be useful in establishing the proper timing of fungicides such as azoxystrobin, which is highly efficacious (28). Because the infections that are most likely to become symptomatic occur early in the growing season, fungicide applied immediately following emergence may be the most effective.

\section{ACKNOWLEDGMENTS}

We thank D. Peterson, R. Sherman, R. Benz, D. Serfling, and R. Nilles for technical assistance in conducting these experiments; C. Doetkott for assistance with statistical analyses; and the Minnesota Area II Potato Growers Association and the Northern Plains Potato Growers Association for funding this research.

\section{LITERATURE CITED}

1. Andrivon, D., Lucas, J. M., Guerin, C., and Jouan B. 1998. Colonization of roots, stolons, tubers and stems of various potato (Solanum tuberosum) cultivars by the black dot fungus Colletotrichum coccodes. Plant Pathol. 47:440445.

2. Aqeel, A. M., Pasche, J. S., and Gudmestad, N. C. 2008. Variability in morphology and aggressiveness among North American vegetative compatibility groups of Colletotrichum coccodes. Phytopathology 98:901-909.

3. Barkdoll, A. W., and Davis, J. R. 1992. Distribution of Colletotrichum coccodes in Idaho and variation of pathogenicity on potato. Plant Dis. 76:131-135.

4. Cullen, D. W., Lees, A. K., Toth, I. K., and Duncan, J. M. 2002. Detection of Colletotrichum coccodes from soil and potato tubers by conventional and quantitative real-time PCR. Plant Pathol. 51:281-292.

5. Cummings, T. F., and Johnson, D. A. 2008 Effectiveness of early-season single applications of azoxystrobin for the control of potato black dot as evaluated by three assessment methods. Am. J. Pot. Res. 85:422-431.

6. Dashwood, E. P., Fox, R. A., and Perry, D. A. 1992. Effect of inoculum source on root and tuber infection by potato blemish disease fungi. Plant Pathol. 41:215-223.

7. Davis, J. R., and Everson, D. O. 1986. Relationship of Verticillium dahliae in soil and potato tissue, irrigation method, and N-fertility to Verticillium wilt of potato. Phytopathology 76:730-736.

8. Davis, J. R., and Howard, M. N. 1976. Presence of Colletotrichum atramentarium in Idaho and relation to Verticillium wilt (Verticillium dahliae). Am. Potato J. 53:397-398.

9. Davis, J. R., and Johnson, D. A. 2001. Black dot. Pages 16-18 in: Compendium of Potato Diseases. W. R. Stevenson, R. Loria, G. D Franc, and D. P. Weingartner, eds. American Phytopathological Society, St. Paul, MN.

10. Davis, J. R., Pavek, J. J. Corsini, D. L., Sorensen, L. H., Schneider, A. T., Everson, D. O., Westerman, D. T., and Huisman, O. C. 1994. Influence of continuous cropping of several potato clones on the epidemiology of Verticillium wilt of potato. Phytopathology 84:207214.

11. Denner, F. D. N., Millard C. P., and Wehner, F. C. 1998. The effect of seed- and soilborne inoculum of Colletotrichum coccodes on the incidence of black dot on potatoes. Potato Res. 41:51-56. 
12. Denner, F. D. N, Millard, C. P., and Wehner, F. C. 2000. Effect of soil solarization and mouldboard ploughing on black dot of potato caused by Colletotrichum coccodes. Potato Res. 43:195-201.

13. Dickson, B. T. 1926. The black dot disease of potato. Phytopathology 16:23-40.

14. Dillard, H. R., and Cobb, A. C. 1998. Survival of Colletotrichum coccodes in infected tomato tissue and in soil. Plant Dis. 82:235-238.

15. Eberlein, C. V., Barkdoll, A. W., and Davis, J. R. 1991. Pathogenicity of Colletotrichum coccodes isolates to potato (Solanum tuberosum) and two nightshade (Solanum spp.) species. Weed Technol. 5:570-574.

16. Farley, J. D. 1972. A selective medium for assay of Colletotrichum coccodes in soil. Phytopathology 62:1288-1293.

17. Farley, J. D. 1976. Survival of Colletotrichum coccodes in soil. Phytopathology 66:640-641.

18. Glais, I., and Andrivon, D. 2004. Deep sunken lesions-an atypical symptom on potato tubers caused by Colletotrichum coccodes during storage. Plant Pathol. 53:254.

19. Heilmann, L. J., Nitzan, N., Johnson, D. A., Pasche, J. S., Doetkott, C., and Gudmestad, N. C. 2006. Genetic variability in the potato pathogen Colletotrichum coccodes as determined by amplified fragment length polymorphism and vegetative compatibility group analysis. Phytopathology 96:1097-1107.

20. Hunger, R. M., and McIntyre, G. A. 1979. Occurrence, development, and losses associated with silver scurf and black dot on Colorado potatoes. Am. Potato J. 56:289-306.

21. Johnson, D. A. 1994. Effect of foliar infection caused by Colletotrichum coccodes on yield of Russet Burbank potato. Plant Dis. 78:10751078 .

22. Johnson, D. A., and Miliczky, E. R. 1993. Distribution and development of black dot, Verticillium wilt, and powdery scab on Russet Burbank potatoes in Washington State. Plant Dis. 77:74-79.

23. Johnson, D. A., and Miliczky, E. R. 1993. Effects of wounding and wetting duration on infection of potato foliage by Colletotrichum coccodes. Plant Dis. 77:13-17.

24. Komm, D. A., and Stevenson, W. R. 1978. Tuber-borne infection of Solanum tuberosum 'Superior' by Colletotrichum coccodes. Plant Dis. Rep. 62:682-687.

25. Lees, A. K., and Hilton, A. J. 2003. Black dot (Colletotrichum coccodes): an increasingly important disease of potato. Plant Pathol. 52:312

26. Miller, P. M. 1955. V8 juice agar as a general purpose medium for fungi and bacteria. Phytopathology 45:461-462.
27. Mohan, S. K., Davis, J. R., Sorensen, L. H., and Schneider, A. T. 1992. Infection of aerial parts of potato plants by Colletotrichum coccodes and its effects on premature vine death and yield. Am. Potato J. 69:547-559.

28. Nitzan, N., Cummings, T. F., and Johnson, D. A. 2005. Effect of seed-tuber generation, soilborne inoculum, and azoxystrobin application on development of potato black dot caused by Colletotrichum coccodes. Plant Dis. 89:11811185 .

29. Nitzan, N., Cummings, T. F., and Johnson, D. A. 2008. Disease potential of soil- and tuberborne inocula of Colletotrichum coccodes and black dot severity on potato. Plant Dis. 92:1497-1502.

30. Nitzan, N., Evans, M. A., Cummings, T. F., Johnson, D. A., Batchelor, D. L., Olsen, C., Haynes, K. G., and Brown, C. R. 2009. Field resistance to potato stem colonization by the black dot pathogen Colletotrichum coccodes. Plant Dis. 93:1116-1122.

31. Nitzan, N., Evans, M., and Johnson, D. A 2006. Colonization of potato plants after aerial infection by Colletotrichum coccodes, causal agent of potato black dot. Plant Dis. 90:9991003

32. Nitzan, N., Hazanovsky, M., Tal, M., and Tsror (Lahkim), L. 2002. Vegetative compatibility groups in Colletotrichum coccodes, the causal agent of black dot on potato. Phytopathology 92:827-832.

33. Nitzan, N., Lucas, B. S., and Christ, B. J. 2006. Colonization of rotation crops and weeds by the potato black dot pathogen Colletotrichum coccodes. Am. J. Potato Res. 83:503-507.

34. Nitzan, N., Tsror (Lahkim), L., and Johnson, D. A. 2006c. Vegetative Compatibility groups and aggressiveness of North American isolates of Colletotrichum coccodes, the causal agent of potato black dot. Plant Dis. 90:1287-1292.

35. Otazu, V., Gudmestad, N. C., and Zink, R. T. 1978. The role of Colletotrichum atramentarium in the potato wilt complex in North Dakota. Plant Dis. Rep. 62:847-851.

36. Pavlista, A. D., and Kerr, E. D. 1992. Black dot of potato caused by Colletotrichum coccodes in Nebraska. Plant Dis. 76:1077.

37. Raid, R. N., and Pennypacker, S. P. 1987. Weeds as hosts of Colletotrichum coccodes. Plant Dis. 71:643-646.

38. Read, P. J., and Hide, G. A. 1988. Effects of inoculum source and irrigation on black dot disease of potatoes (Colletotrichum coccodes (Wallr.) Hughes) and its development during storage. Potato Res. 31:493-500.

39. Read, P. J., and Hide, G. A. 1995. Development of black dot disease (Colletotrichum coc- codes (Wallr.) Hughes) and its effects on the growth and yield of potato plants. Ann. Appl. Biol. 127:57-72.

40. Rich, A. E. 1983. Potato Diseases. Academic Press, Inc., New York.

41. Rothrock, C. S. 1992. Tillage systems and plant disease. Soil Sci. 154:308-315.

42. Rowe, R. C., Davis, J. R., Powelson, M. L., and Rouse, D. I. 1987. Potato early dying: causal agents and management strategies. Plant Dis. 71:482-489.

43. Scholte, K., Veenbaas-Rijks, J. W., and Labruyere, R. E. 1985. Potato growing in short rotations and the effects of Streptomyces spp., Colletotrichum coccodes, Fusarium tabacinum and Verticillium dahliae on plant growth and tuber yield. Potato Res. 28:331-348.

44. Shaner, G., and Finney, R. E. 1977. The effect of nitrogen fertilization on the expression of slow-mildewing resistance in Knox wheat Phytopathology 67:1051-1056.

45. Smith, D. 1984. Maintenance of fungi. Pages 83-107 in: Maintenance of Microorganisms. B E. Kirsop and J. J. S. Snell, eds. Academic Press, London.

46. Stevenson, W. R., Green, R. J., and Bergeson, G. B. 1976. Occurrence and control of potato black dot root rot in Indiana. Plant Dis. Rep. 60:248-251

47. Taylor, R. J., Pasche, J. S., and Gudmestad, N. C. 2005. Influence of tillage and method of metam sodium application on distribution and survival of Verticillium dahliae in the soil and the development of Verticillium wilt of potato. Am. J. Potato Res. 82:451-461.

48. Thirumalachar, M. S. 1967. Pathogenicity of Colletotrichum atramentarium on some potato varieties. Am. Potato J. 44:241-244.

49. Tsror (Lahkim), L. 2004. Effect of light duration on severity of black dot caused by Colletotrichum coccodes on potato. Plant Pathol. 53:288-293.

50. Tsror (Lahkim), L., Elrich, O., and Hazanovsky, M. 1999. Effect of Colletotrichum coccodes on potato yield, tuber quality and stem colonization during spring and autumn. Plant Dis. 83:561-565.

51. Tsror (Lahkim), L., and Hazanovsky, M. 2001. Effect of coinfection by Verticillium dahliae and Colletotrichum coccodes on disease symptoms and fungal colonization in four potato cultivars. Plant Pathol. 50:483-488.

52. Tsror (Lahkim), L., and Johnson, D. A. 2000 Colletotrichum coccodes on potato. Pages 362 373 in: Colletotrichum: Host Specificity, $\mathrm{Pa}$ thology, and Host-Pathogen Interaction. D. Prusk, S. Freeman, and M. B. Dickman, eds. American Phytopathological Society, St. Paul, MN. 